\title{
Discussion on Teaching Mode of the Foundation of Computer Courses in Micro Class Age
}

\author{
Xiaohong ZHOU \\ Department of Computer Fundament Education, Shenzhen Polytechnic University, Guangdong, China
}

\begin{abstract}
Micro class have been popular in the field of education, In the limited teaching time, how to combine the micro class and the traditional class, bring up students' computer application ability and solve problem ability, is urgent to solve problems in the teaching of the foundation of computer courses. This paper analysis the purpose of teaching, the present teaching status, the characteristics of micro class, advantage of application in the higher occupation education, Finally, listed teaching mode of higher vocational education under the support of micro class, including application mode, selection principle of knowledge and teaching design.
\end{abstract}

KEYWORD: Micro class; higher occupation education; the foundation of computer courses

\section{FOUNDATION OF COMPUTER COURSES TEACHING STATUS IN VOCATIONAL COLLEGES}

Computer course is very important in both improving the computer literacy of non-computer major student and improving students' learning ability in computer-related courses. Besides, its improvement in solving and dealing with the problems in the professional courses using computers is becoming more and more significant. However, the development of computer teaching has been limited by the Basic computer courses teaching status, specifically in the following aspects.

\subsection{The individual differences of students haven't been considered by the current knowledge system and syllabus}

The basic computer knowledge of students is different. This difference is not only caused by the different economic and cultural development of varies regions in our country but also due to the individual problems of the students. Therefore, during the study, part of the students feel more difficult to understand the computer knowledge, while some others feel the knowledge is too simple or obsolete. It is difficult to grasp and choose the teaching content, hardly satisfy the leaning requirements of students with different levels, therefore, the discontent of students to the computer courses are inevitable.

\subsection{The deepening conflict between teaching contents and spend time.}

As the innovation and development of technology and theory, the teaching contents of computer basic course have an explosive increment. Meanwhile, the seeking knowledge desire of new generation of college students is growing, however, the teaching classes has reduced instead of increasing, which makes finishing the basic computer teaching contents in a limited teaching classes getting more and more difficult.

\subsection{Individual differences of students lead to low efficiency of teaching}

Due to the differences of student in learning ability, knowledge basis and self-discipline ability, the teaching organization and teaching management is getting more and more difficult to perform. Some courses were arranged to be finished by students' self-learning after class, however, around half of the students can not finish, which bring great resistance to the teaching of subsequent courses, make the follow-up courses hard to be executed as planned and finally lead to a low level of both the classroom teaching quality and efficiency. At present, this kind of situation continues to deteriorate. 


\subsection{Teaching methods can't match with the characteristics of course.}

The teaching methods of computer basic courses contain "demonstration method", "task-driven method", "explore-research method", etc. However, the "talking-practice method" and "practice after talking method" are mostly used for practical teach. For the "talking-practice method", the students "learn quickly but forget faster", it is difficult for them to form a complete knowledge system and build the learning ability. For the "practice after talking method", after been taught too much content, students' operation should rely on their memory and understanding of the course content, which is easily to forget. However, as a practical and operational course, the computer foundation courses can't be mastered until persistent observation, demonstration and practical operation [3].

\subsection{The case teaching method is not conducive in mastering key and difficult knowledge points}

Case teaching method has been widely used in the vocational colleges. Use this method, the knowledge can be guided following the cases, which discover the students with the necessity and practicability of the learning content, overcome the disadvantage of "the endless attention to trees at the expense of forests" in knowledge teaching method. However, the interesting and practical in case teaching method made the student tend to focus on the interesting of case and ignore the original purpose to design the case. Therefore, the students didn't pay more attention to the comprehensive grasp and flexible application of knowledge points, and didn't focus on a deeper and wider application of the knowledge in the case, which couldn't reach the planed teaching effect.

\subsection{Existing network learning resources need to be improved}

The existing highquality course website contains rich resources of network teaching. However, most of the videos' time is too long, which content too much knowledge points, the teaching topic is not outstanding and the teaching goal is not clear. On one hand, the time of video didn't match with the students' cognitive characteristics; on the other hand, the content of video is not in conformity with the learning foundation of students in higher vocational collage.

Therefore, the classroom teaching and network resource mode construction in vocational colleges shouldn't stick to the traditional mode, which should try to use education information technology, integrate the classroom teaching content and the network learning content reasonably, design network learning resources carefully.

\section{THE ADVANTAGE OF MICRO-COURSE IN VOCATIONAL COLLEGES}

According to their own teaching experience, teachers designed series of novel types of micro videos (micro class) to solving the key points (key points, difficult points, etc.) during teaching. It has broken the construction model of traditional network resources, and was considered as an evolution of the traditional video teaching in the micro era. Compared with students in the ordinary undergraduate colleges, the learning motivations of students in vocational collage mostly depend on their interesting in the learning content. Generally, they are more interested in practical courses and show good network operation skill and high ability in the digital survival and learning. However, in the study of the course content of boring knowledge and theory, they exhibit very low efficiency, and lack of perseverance and selfdiscipline. They don't like the traditional school classroom teaching method, mostly tend to learning from practice and won't learn until facing the problems. Some students want to learn, but their incoherent foundation makes them hard to master the knowledge, thus lose their interest in learning.

The micro class can solve the current teaching problems existing in the higher vocational colleges, and provide new ideas for classroom teaching. The micro class shows three benefits. For the students' learning, the micro class can meet the learning characteristics of higher vocational students. For the teacher' quality, the micro class can promote teachers' professional development by sharing highquality resources. For the student-teacher interactive, the micro class can be used as the carrier to change the existing classroom teaching mode.

Considering the students' learning ability, knowledge foundation, learning interest and the current situation of basic computer courses teaching in vocational colleges, the application of micro class as auxiliary teaching method has following advantages:

\subsection{A good implementation of the "mastery learning" education philosophy}

Bloom said, "The students' learning levels are not determined by the absolute time spend on learning, the required learning time for each student should be confirmed". The task of "mastery learning" strategy is provide the way to confirm the required learning time for each student. "Micro class" has taken into account of the differences of individual vocational college students and the differences between students' learning interest and methods. The application of micro class is one effective way to realize the concept of "mastery learning" education mode. Students can watch the video repeat and adjust the speed of video, according to their own 
mater situation. In this way, a "required learning time" method can be applied for each student, no matter the levels of learning basic and learning capacity of students. The students can spend "required learning time" in reality and adjust the schedule according to their interest. All the students could master knowledge using the micro class method.

\subsection{Meet the Learners' Cognitive Load Theory}

According to the cognitive load theory, the influencing factors of cognitive load including the presentation of learning content, the complexity of learning content, and the learner's knowledge bases. Teaching design is very important because the teaching information should meet the requirement of limited working memory, and the presentation of teaching content should be remembered easily. Using the ideal teaching mode, learners should carry on a full load study flexibly for some valuable key and difficult points. For this teaching mode, a long learning time is not necessary.

The "short" and "focus" characters of micro class can solve the learners' cognitive load problem well, which make the learner study in the limit of work memory. Also, the micro class conforms to the cognitive characteristics of students in vocational colleges.

\subsection{Provide sufficient condition to "reform the class structure and study mode"}

By application of the information technology to education, the traditional classroom teaching structure can be reformed and rebuilt. According to the mainstream leading study theory, the role of students should be transferred from a passive learner to an independent knowledge constructer; the role of teachers should be transferred from a dominator to a promoter and helper; more inspiring and discussion teaching active should be carried out [2].

\section{CONSTRUCTION OF COMPUTER APPLICATION COURSE'S TEACHING MODE SUPPORTED BY MICRO CLASS}

At present, the teaching content of computer application contains four parts, they are: office software, computer basic knowledge, operating system and computer network. Those points are relatively independent and show high maneuverability. For most of them, the hardware resources are not necessary and the micro class teaching mode is quite suitable.

\subsection{Application of micro class in the "computer application course"}

The micro class is being applied in two ways at present. First, it is acting as an auxiliary to the traditional teaching method. It liberates teachers from repeating on certain knowledge points, and provides the students with resource for review after class. Second, the micro class is used as study resource and arranged to the students for their selfstudy before class; while, in the class, the application and practice of knowledge points are discussed and analyzed by the teachers. The latter way has changed the "organization of classroom teaching mode" in a deeper level.

In the classroom teaching of computer application course in vocational college, those two ways mentioned above can be combined effectively by choosing different application ways of micro class according to the different knowledge contents. This combination can not only overcome the confusion of teaching caused by students' different level, but also can build the self-study capacity of students.

(1) Intersperse in the traditional classroom teaching with micro class

Research showed that, generally the maximum last time for human to keep attention is around ten minutes. It is almost impossible to keep students' attention all through the traditional class (fifty minutes). However, if teachers can intersperse some micro classes during the teaching, the classroom atmosphere can be adjusted and the students' attention can be grasped [1].

(2) Auxiliary resource for preview and review

For difficult and complex knowledge, it is difficult to achieve the desired effect using the traditional teaching mode. Once been made as micro class, it can be studied out of the classroom teaching, including preview and review. In this way, both the teaching quality and the progress of the classroom teaching can be ensured, meanwhile, the confusion of teaching caused by students' different level can be overcome[2].

(3) Learning at any time

With strong proliferation thought, the post-90 college students have great pursuit of freedom and personalized. Compared with the traditional boring teaching mode, they prefer to the diversity of teaching mode. Because of its short and concise, the micro class can be easily upload and download, which can be watched on the smart phones and tablets. It made the students learn whenever and whenever they are [1].

\subsection{The selection of knowledge points for micro class in "computer application course"}

Take the micro class of "design using WORD" as an example, the basis of selecting and the method of classifying knowledge points are illustrated. 
Table 1. The selection of knowledge points

\begin{tabular}{|c|c|}
\hline $\begin{array}{l}\text { Key points } \\
\text { Difficult points }\end{array}$ & Expeditions improvements \\
\hline $\begin{array}{l}\text { Key points } \\
\text { Mixed map and text } \\
\text { Mail merge } \\
\text { Creation of forms } \\
\text { Difficult points } \\
\text { Application of section break } \\
\text { Insertion of complex page } \\
\text { header and footer } \\
\text { Style and Application of } \\
\text { multistage number }\end{array}$ & $\begin{array}{l}\text { Application of searching/replace } \\
\text { Application of domain } \\
\text { Input and output of style } \\
\text { The production and application } \\
\text { of document template }\end{array}$ \\
\hline
\end{tabular}

The micro class of "key points" can be arranged to the students for their preview. In the classroom teaching, using some teaching activities, such as scene introduction and case demonstration, students can mater the knowledge points directly. Teachers can inspire the students a deeper thought. The micro class of "difficult points" can be explained by teachers in classroom teaching, which can be also arranged to the students for their review after class. The micro class of "Expeditions and improvement" is useful to do self-study for the students with good knowledge foundations.

\subsection{Design of micro class teaching}

Using the excellent micro class, the students achieve not only the knowledge and technology, but also an effective study habits and good professional quality.

Take the way to add animation effects in slide as an example, the design of micro class will be illustrated.

Table 2. Instructional design

\begin{tabular}{|c|}
\hline $\begin{array}{l}\text { Name of micro class: } \\
\text { The production of "Snow" scene animation }\end{array}$ \\
\hline $\begin{array}{l}\text { Name of knowledge point: } \\
\text { The realization of the custom animation }\end{array}$ \\
\hline $\begin{array}{l}\text { Teaching goals: } \\
\text { 1. Master the design method of animation; } \\
\text { 2. Flexible application of animation to enhance the effect of the } \\
\text { presentation. }\end{array}$ \\
\hline $\begin{array}{l}\text { 3. Teaching process: } \\
\text { Analysis the ideas, determine the realization steps } \\
\text { Extrication and Explanation of knowledge points } \\
\text { Application case of "animating brushes" } \\
\text { Conclusion and expeditions of knowledge points }\end{array}$ \\
\hline $\begin{array}{l}\text { Design concept: } \\
\text { By constructing reasonable cases, contains the knowledge points used } \\
\text { during the process of animation production as much as possible. } \\
\text { Using lively and interesting cases, cultivate students' interest in } \\
\text { learning the knowledge points. } \\
\text { Lead and develop the students' design ideas, encourage them to use the } \\
\text { knowledge in real life and work flexibly. }\end{array}$ \\
\hline
\end{tabular}

\section{CONCLUSION}

With rapid development of information technology, the application of micro class in teaching is a tendency of the integration of information technology and curriculum. With the characters of "short and concise" and the design concept of "all can learn, all want to learn", the micro class has a rapid popularization in teaching. Design of high quality micro class can effectively solve the contradiction between teaching contents and teaching classes, solve the confusion of teaching caused by students' different level. Teachers can cultivate students' ability of computer application and solve reality problems in a limited teaching time, hence built the students' autonomous learning ability and habit. However, the micro class can't replace the classroom teaching, which should take root in the reality class teaching and be used as a complement and expansion for the traditional teaching.

\section{REFERENCES}

[1] Bo Dai, Discussion on the class teaching mode integrated with traditional teaching method and modern education technology, Heilongjiang Education (Higher Education Research \& Appraisal), 2013, 9.

[2] Cuifeng $\mathrm{Xu}$, Qing Guo. The theory of micro lessons and effective integration of traditional teaching, Career Horizon, 2014, 10(1).

[3] Leming Liang. From resources construction to application: current situation and development trend of micro class, China Educational Technology, 2013, (8): 71-76. 